\title{
Computed Tomography-based Assessment of Radiographic Progression in Spine and Sacroiliac Joints After Pregnancy in Women With Ankylosing Spondylitis
}

\section{Kyung-Ann Lee}

Soonchunhyang University Hospital https://orcid.org/0000-0001-7499-6363

\section{So Yun Lee}

Kyung Hee University Gangdong Hospital: Kyung Hee University Hospital at Gangdong

\section{Se Hee Kim}

Konkuk University Seoul Hospital: Konkuk University Medical Center

\section{Hyun-Sook Kim}

Soonchunhyang University Hospital Seoul: Soonchunhyang University Hospital

\section{Hae-Rim Kim}

Konkuk University Seoul Hospital: Konkuk University Medical Center

\section{Sang-Hoon Lee ( $\sim$ boltaguni@gmail.com )}

Kyung Hee University Gangdong Hospital: Kyung Hee University Hospital at Gangdong https://orcid.org/0000-0003-3655-9546

\section{Research article}

Keywords: Ankylosing spondylitis, pregnancy, computed tomography, spine, sacroiliac joint

Posted Date: April 8th, 2021

DOl: https://doi.org/10.21203/rs.3.rs-377242/v1

License: (ㅇ) (1) This work is licensed under a Creative Commons Attribution 4.0 International License. Read Full License 


\section{Abstract}

Background: Mechanical stress are one of the pathogenesis of ankylosing spondylitis (AS). During pregnancy, the mechanical overload on the spine and pelvis increases due to gravid uterus. We aimed to investigate whether pregnancy affects radiographic progression in patients with ankylosing spondylitis (AS) based on computed tomography (CT) evaluations.

Methods: This retrospective study included women with AS aged 19-49 years who underwent at least two CT evaluations of the whole spine or sacroiliac joints (SIJs) at intervals of 2-4 years. To compare radiographic progression after delivery, we classified the patients into two groups: delivery group and controls. The delivery group was restricted to women who had the first CT $\sim 2$ years before delivery and the second CT $\sim 2$ years after delivery. The CT Syndesmophyte Score (CTSS) (0-522) and SIJ scores (0-40) were used to evaluate spinal syndesmophytes and erosion, joint space narrowing, and sclerosis of the SIJs.

Results: A total of 21 women in the delivery group and 38 women in the control group were included. The median (Q1-Q3) CTSS at baseline in the delivery group and controls was 19 (16-23) and 20 (13.25-27.75), and the median progression was 1 (0-3) and 0 (0-1) during the median 2.9-year follow-up, respectively. The median (Q1-Q3) SIJ score at baseline in the delivery group and controls was 13 (8-22) and 11 (6-22), and the median progression was $1.5(0-3)$ and $1(0-2)$, respectively. The CTSS and SIJ scores significantly increased in both groups; however, no difference in absolute score changes per time point was observed. The SIJ score changes were comparable according to the delivery method.

Conclusion: Pregnancy and delivery do not affect the radiographic progression of the spine and SIJs in women with AS.

\section{Background}

Ankylosing spondylitis (AS) is a chronic inflammatory arthritis affecting the sacroiliac joints (SIJs) and the spine, commonly occurring in childbearing age [1]. Although AS was previously believed to predominantly affect men, recent studies have shown that the incidence of AS in women is as high as one in every three women [2]. Pregnancy is a major issue faced by female AS patients of childbearing age.

Mechanical stress is one of the causes of AS [3]. During pregnancy, the mechanical load on the spine and pelvis increases because of the gravid uterus. During pregnancy and after childbirth, almost half of pregnant women experience pain in the lumbar and/or sacroiliac area and/or in the symphysis pubis [4]. More women with AS discontinue medications during pregnancy than women with systemic lupus erythematosus and rheumatoid arthritis [5], and tumor necrosis factor inhibitor (TNFI) discontinuation in early pregnancy has been identified as a risk factor for disease flares during pregnancy [6]. Previous studies on the effects of pregnancy in patients with AS have focused on disease activity during pregnancy, pregnancy outcomes (e.g., rates of cesarean section [CS], preterm birth, and preeclampsia), and fetal outcomes (e.g., low birth weight and congenital abnormalities) [6-8]. However, to our knowledge, the possible influence of pregnancy on radiographic progression in patients with AS has not yet been documented. 
Recently, the Computed Tomography (CT) Syndesmophyte Score (CTSS) was developed to analyze spinal damage in patients with AS [9]. Although the modified Stoke Ankylosing Spondylitis Spine Score (mSASSS) includes the evaluation of lateral views of the cervical and lumbar spine segments, the CTSS has the advantage of evaluating bone proliferation in the entire spine, including the thoracic spine, at four quadrants (anterior, posterior, left, and right) with excellent reliability $[10,11]$. With respect to imaging evaluation of the SIJs, CT has higher sensitivity and reliability than conventional radiography in detecting sacroiliitis [12, 13].

In this study, we aimed to investigate whether pregnancy and delivery affect the radiographic progression of the spine and SIJs in women with AS based on CT evaluations.

\section{Methods}

\section{Study design and population}

This retrospective study included women aged 19-49 years who were diagnosed with AS according to the modified New York criteria at Gangdong Kyung Hee University Hospital and Konkuk University Medical Center, South Korea, between February 2009 and August 2020 [14]. To be included in this study, patients should have undergone at least two CT evaluations of the whole spine or SIJs at intervals of 2-4 years.

To compare radiographic progression after delivery, we classified the patients into two groups: delivery group and control group. The delivery group was restricted to women who had the first CT evaluation at a maximum of 2 years before delivery and the second CT evaluation at a maximum of 2 years after delivery. Controls were defined as women who had two CT evaluations with 2-4-year intervals. Demographic characteristics (age and smoking), clinical data (disease duration and extra-articular manifestations), method of delivery (vaginal delivery [VD] or CS), laboratory data (human leukocyte antigen-B27 [HLA-B27], C-reactive protein [CRP], and time-averaged CRP), and treatments were collected from the complete medical records. Time-averaged CRP was defined as the mean CRP level during the CT intervals [15]. The normal range of CRP was defined as 0-0.5 $\mathrm{mg} / \mathrm{dL}$. CRP elevations related to infections or medical interventions, based on a retrospective chart review, were excluded from the analysis. The treatment strategies used were classified as continuous, on-demand, or discontinued treatment.

This study was conducted in accordance with the Declaration of Helsinki and approved by the institutional review boards (IRBs) of Gangdong Kyung Hee University Hospital (2019-08-012) and Konkuk University Medical Center (KUH1011006). The need for informed consent was waived under the IRB authority owing to the retrospective nature of the study and because the analysis used anonymous clinical data.

\section{CT scoring system}

The CTSS, ranging from 0 to 552, was used to compare the radiographic progression of the whole spine [9]. The anterior and posterior quadrants from the bottom half of $\mathrm{C} 2$ to the top half of S1 were scored in the coronal and sagittal planes (23 vertebral units [VUs] in total), scoring eight quadrants per VU. The score reflects the height of a syndesmophyte relative to the intervertebral disc space (IDS). For every quadrant, the score was 0 if no syndesmophyte was present, 1 if a syndesmophyte was present but did not reach $50 \%$ of 
the IDS, 2 if the syndesmophyte reached or crossed $50 \%$ of the IDS, and 3 if the syndesmophyte bridged the IDS.

The SIJs were divided into the left and right segments and the iliac and sacral segments, for a total of four segments. The scoring of the radiographs considered erosions, joint space alterations, and sclerosis. Erosions were graded from 0 to 3 (grade 0 , no erosions; grade 1, small, isolated erosions [1-2] or a questionable single erosion; grade 2, definite erosions [3-5; $<3 \mathrm{~mm}$ ] or a larger single erosion [ $>3 \mathrm{~mm}$; and grade 3 , multiple [ $>5]$ or confluent erosions). Each of the four segments was independently assessed for the slice with the maximum number of erosions in both the transverse and coronal views. By adding the number of erosions in all four segments in both transverse and coronal views, the total erosion score (TES) was calculated (0-24). The joint space alterations were graded from 0 to 4 (grade 0 , no joint space changes; grade 1, questionable widening or narrowing; grade 2, pseudo-widening; grade 3, partial ankyloses; and grade 4, extensive/total ankyloses). Ankylosis was defined as $>1 \mathrm{~cm}$ of marrow contiguous between the sacral and iliac sides. Extensive ankylosis was defined as affecting at least half of the joints. Sclerosis in the coronal view was graded from 0 to 2 (grade 0 , no sclerosis; grade 1, questionable or little sclerosis [ $\geq 5 \mathrm{~mm}$ ]; and grade 2, evident sclerosis [ $\geq 10$ $\mathrm{mm}]$ ) [13]. The total SIJ score ranged from 0 to 40.

The CT scans were independently scored by two readers (K.A. Lee and S.Y. Lee). The readers were blinded to patient characteristics, clinical data, and findings of other imaging modalities.

\section{CT scanning technique}

The CT scans and radiographs were read using a Digital Imaging and Communications in Medicine viewer. CT evaluations were performed with contiguous slices of 2-mm thickness. All spinal CT scans included a complete vertebral column. Because this study utilized preexisting scans, radiation exposure was not controlled and images of the SIJs were not reformatted into a semicoronal view.

\section{Statistical analysis}

Statistical analyses were performed using SPSS for Windows (version 22.0; SPSS Inc., Chicago, IL, USA). Continuous variables are expressed as medians (Q1-Q3), and categorical variables are presented as frequencies and proportions. The results were compared using Pearson's chi-square test, Fisher's exact test, and the Mann-Whitney $\mathrm{U}$ test or Kruskal-Wallis test, as appropriate, for significant differences in patient characteristics between the delivery group and the control group. Interreader reliability was assessed using the intraclass correlation coefficient (ICC). The CT scores between the two time points were compared using the paired Wilcoxon test. The average score was used for the analysis. Statistical significance was set at $p<0.05$.

\section{Results}

\section{Baseline characteristics}

A total of 45 women with AS had both spine and pelvic CT evaluations at baseline and follow-up (minimum 2 years, maximum 4 years): delivery group $(n=17)$ and controls $(n=28)$. Fifteen women with AS had only pelvic CT at baseline and follow-up: delivery group $(n=5)$ and controls $(n=10)$. Table 1 summarizes the baseline 
characteristics of the study population. The median (Q1-Q3) age of the AS patients in the delivery and control groups was 32 (30-34.25) and 30 (26-34.25) years, with a median (Q1-Q3) disease duration of 3 (0.87-6.0) and 1 (0.17-3.0) years, respectively. The median (Q1-Q3) interval time between the first and second CT in the delivery and control groups was $2.96(2.33-3.47)$ and $2.95(2.43-3.33)$ years, respectively. 
Table 1

Baseline characteristics of women with ankylosing spondylitis included in the analyses

\begin{tabular}{|c|c|c|c|}
\hline & $\begin{array}{l}\text { Delivery } \\
(n=21)\end{array}$ & $\begin{array}{l}\text { Controls } \\
(n=38)\end{array}$ & $\begin{array}{l}P \text { - } \\
\text { value }\end{array}$ \\
\hline \multicolumn{4}{|l|}{ Demographic variables } \\
\hline Age at baseline $C T$, years & $32(30-34.25)$ & $30(26-34.25)$ & 0.072 \\
\hline Smoking & $0(0)$ & $1(2.6)$ & 1.000 \\
\hline Interval time between the $1 \mathrm{st}$ and $2 \mathrm{nd}$ CT, years & $\begin{array}{l}2.96(2.33- \\
3.47)\end{array}$ & $\begin{array}{l}2.95(2.43- \\
3.33)\end{array}$ & 0.818 \\
\hline \multicolumn{4}{|l|}{ Disease-related variables } \\
\hline Disease duration, years & $3(0.87-6.0)$ & $1(0.17-3.0)$ & 0.083 \\
\hline HLA-B27 positive & $20(95.2)$ & $33(86.8)$ & 0.407 \\
\hline History of Uveitis & $7(33.3)$ & $14(36.8)$ & 0.694 \\
\hline History of Psoriasis & $0(0)$ & $1(2.6)$ & 1.000 \\
\hline History of IBD & $0(0)$ & $1(2.6)$ & 1.000 \\
\hline History of enthesitis & $6(28.6)$ & $8(21.1)$ & 0.583 \\
\hline History of peripheral arthritis & $5(23.8)$ & $11(28.9)$ & 0.600 \\
\hline CRP at baseline $\mathrm{CT}, \mathrm{mg} / \mathrm{dl}$ & $\begin{array}{l}0.32(0.08 \\
0.69)\end{array}$ & $0.27(0.1,0.46)$ & 0.079 \\
\hline CRP at baseline $\mathrm{CT}>0.5 \mathrm{mg} / \mathrm{dl}, \mathrm{n}(\%)$ & $8(38.1)$ & $7(18.4)$ & 0.122 \\
\hline CRP at follow-up CT, mg/dl & $\begin{array}{l}0.11(0.07 \\
0.75)\end{array}$ & $\begin{array}{l}0.05(0.04 \\
0.30)\end{array}$ & 0.034 \\
\hline CRP at follow-up CT >0.5 mg/dl, n (\%) & $6(28.6)$ & $3(7.9)$ & 0.063 \\
\hline Time-average CRP during follow-up, $\mathrm{mg} / \mathrm{dl}$ & $\begin{array}{l}0.36(0.25 \\
0.57)\end{array}$ & $\begin{array}{l}0.17(0.12 \\
0.34)\end{array}$ & 0.006 \\
\hline Time-average CRP during follow-up > $0.5 \mathrm{mg} / \mathrm{dl}, \mathrm{n}(\%)$ & $7(33.3)$ & $6(15.8)$ & 0.197 \\
\hline Treatment during follow-up & & & $\begin{array}{l}< \\
0.001\end{array}$ \\
\hline Continuous treatment & $1(4.8)$ & $30(78.9)$ & \\
\hline On demand treatment & $1(4.8)$ & $1(2.6)$ & \\
\hline Discontinued treatment & $19(90.5)$ & $7(18.4)$ & \\
\hline \multicolumn{4}{|l|}{ Results are presented in median (Q1, Q3) or number (\%). } \\
\hline \multicolumn{4}{|c|}{$\begin{array}{l}\text { CT: computed tomography, HLA-B27: human leucocyte antigen B27, IBD: inflammatory bowel disease, } \\
\text { CRP: C-reactive protein, NSAID: non-steroidal anti-inflammatory drugs, Cox: cyclooxygenase, csDMARD: } \\
\text { conventional synthetic disease modifying antirheumatic drug, TNF: tumour necrosis factor, IL: interleukin }\end{array}$} \\
\hline
\end{tabular}




$\begin{array}{lll}\text { Delivery } & \text { Controls } & \text { P- } \\ (n=21) & (n=38) & \text { value }\end{array}$

Stop duration in patients who discontinued treatment, months

$12(9.5,24.0) \quad 14(10.5,18)$

0.760

\section{Medication during follow-up}

$\begin{array}{llll}\text { NSAID/Cox-2 inhibitor } & 13(61.9) & 32(84.2) & 0.030 \\ \text { CSDMARD } & 7(33.3) & 12(31.6) & 0.985 \\ \text { TNF-alpha blocker } & 2(9.5) & 9(23.7) & 0.299 \\ \text { IL-17 inhibitor } & 0(0) & 1(2.6) & 1.000\end{array}$

Results are presented in median (Q1, Q3) or number (\%).

CT: computed tomography, HLA-B27: human leucocyte antigen B27, IBD: inflammatory bowel disease, CRP: C-reactive protein, NSAID: non-steroidal anti-inflammatory drugs, Cox: cyclooxygenase, csDMARD: conventional synthetic disease modifying antirheumatic drug, TNF: tumour necrosis factor, IL: interleukin

No apparent differences were observed between the two groups in terms of HLA-B27 positivity, extra-articular manifestations, CRP levels at baseline CT, medications, and smoking status. The median CRP levels at followup CT and the time-average CRP levels were higher in the delivery group than in controls $(0.11 \mathrm{vs} .0 .05 \mathrm{mg} / \mathrm{dL}$ [ $p=0.034]$ and 0.36 vs. $0.17 \mathrm{mg} / \mathrm{dL}[p=0.006]$, respectively); however, the levels were within the normal range in both groups. In the delivery group, 19 women (90.5\%) discontinued AS medications for a median (Q1-Q3) of $12(9.5-24)$ months because of pregnancy and/or breastfeeding $(n=17)$ and inactive disease $(n=2)$. In the control group, seven women discontinued treatment during the follow-up period because of inactive disease. The median (Q1-Q3) duration of treatment discontinuation was 14 (10.5-18) months.

\section{Reliability}

The interreader reliability is shown in Additional file 1. The ICC for the baseline status score was 0.979 for the whole spine and $0.848-0.963$ for the spine segments. The ICC for the change scores was 0.926 for the whole spine and $0.848,0.940$, and 0.647 for the cervical, thoracic, and lumbar spine segments, respectively. Very good reproducibility was observed in the total score (0.997-0.999), TES (0.994-1.000), joint space narrowing (JSN) score (0.996-0.998), and sclerosis score (0.878-0.992) of the SIJs.

\section{Changes in CT scores of the whole spine over time}


Table 2 shows the median status scores per time point and the change scores for the spine and SIJs. The median (Q1-Q3) baseline status CTSS for the whole spine in the delivery group and controls was 19 (16-23) and $20(13.25-27.75)$, respectively $(p=0.622)$. The total CTSS significantly increased during the median 2.9 years of follow-up in both groups $(p<0.05)$ (Fig. 1). However, no difference in the absolute changes of the CTSS per time point between delivery groups and controls was observed (median [Q1-Q3]: 1.00 [0-3] vs. 0.00 $[0-1])(p=0.343)($ Fig. 2A,B). 
Table 2

Changes in CT scores over time in AS women with and without delivery

\begin{tabular}{|c|c|c|c|c|c|c|c|c|c|}
\hline \multirow[t]{3}{*}{ Spine } & \multirow{2}{*}{\multicolumn{3}{|c|}{$\begin{array}{l}\text { Delivery group } \\
\mathrm{n}=17\end{array}$}} & \multirow{2}{*}{\multicolumn{3}{|c|}{$\begin{array}{l}\text { Control group } \\
n=28\end{array}$}} & \multirow{2}{*}{\multicolumn{3}{|c|}{ Change score }} \\
\hline & & & & & & & & & \\
\hline & Baseline & $\begin{array}{l}\text { Follow- } \\
\text { up }\end{array}$ & $\stackrel{p}{\text { Value }}$ & Baseline & $\begin{array}{l}\text { Follow- } \\
\text { up }\end{array}$ & $\stackrel{p}{\text { Value }}$ & Delivery & Control & $\stackrel{p-}{\text { Value }}$ \\
\hline $\begin{array}{l}\text { Whole } \\
\text { spine (0- } \\
552)\end{array}$ & $\begin{array}{l}19(16- \\
23)\end{array}$ & $\begin{array}{l}20(16- \\
24.5)\end{array}$ & 0.027 & $\begin{array}{l}20 \\
(13.25- \\
27.75)\end{array}$ & $\begin{array}{l}20 \\
(13.25- \\
28)\end{array}$ & 0.005 & $1(0-3)$ & $\begin{array}{l}0(0- \\
1)\end{array}$ & 0.343 \\
\hline $\begin{array}{l}\text { Cervical } \\
\text { spine (0- } \\
144)\end{array}$ & $0(0-2.5)$ & $\begin{array}{l}0(0- \\
3)\end{array}$ & 0.317 & $\begin{array}{l}0(0- \\
1.75)\end{array}$ & $\begin{array}{l}0(0- \\
1.75)\end{array}$ & 0.157 & $0(0-0)$ & $\begin{array}{l}0(0- \\
0)\end{array}$ & 0.553 \\
\hline $\begin{array}{l}\text { Thoracic } \\
\text { spine }(0- \\
264)\end{array}$ & $\begin{array}{l}17(14- \\
20.5)\end{array}$ & $\begin{array}{l}18 \\
(14- \\
22)\end{array}$ & 0.092 & $\begin{array}{l}17 \\
(12.25- \\
24.0)\end{array}$ & $\begin{array}{l}18 \\
(12.25- \\
24.75)\end{array}$ & 0.008 & $\begin{array}{l}0(0- \\
0.5)\end{array}$ & $\begin{array}{l}0(0- \\
1)\end{array}$ & 0.934 \\
\hline $\begin{array}{l}\text { Lumbar } \\
\text { spine (0- } \\
144)\end{array}$ & $1(0-2)$ & $\begin{array}{l}1(0- \\
2.5)\end{array}$ & 0.058 & $0(0-2)$ & $\begin{array}{l}0.5(0- \\
2.75)\end{array}$ & 0.180 & $0(0-0)$ & $\begin{array}{l}0(0- \\
1)\end{array}$ & $0.046 *$ \\
\hline \multirow[t]{3}{*}{ SIJ } & \multicolumn{3}{|c|}{ Delivery group } & \multicolumn{3}{|c|}{ Control group } & \multicolumn{3}{|c|}{ Change score } \\
\hline & \multicolumn{3}{|l|}{$\mathrm{n}=\mathbf{2 1}$} & \multicolumn{3}{|l|}{$n=38$} & & & \\
\hline & Baseline & $\begin{array}{l}\text { Follow- } \\
\text { up }\end{array}$ & $p_{\text {Value }}$ & Baseline & $\begin{array}{l}\text { Follow- } \\
\text { up }\end{array}$ & $\stackrel{p}{\text { Value }}$ & Delivery & control & $\begin{array}{l}p \\
\text { Value }\end{array}$ \\
\hline $\begin{array}{l}\text { Total (0- } \\
40)\end{array}$ & $\begin{array}{l}13(8- \\
22)\end{array}$ & $\begin{array}{l}14 \\
(8.5- \\
20.5)\end{array}$ & 0.048 & $\begin{array}{l}11(6- \\
22)\end{array}$ & $\begin{array}{l}13(6- \\
23.5)\end{array}$ & 0.019 & $\begin{array}{l}1.5(0- \\
3)\end{array}$ & $\begin{array}{l}1(0- \\
2)\end{array}$ & 0.471 \\
\hline $\begin{array}{l}\text { Erosion } \\
(0-24)\end{array}$ & $\begin{array}{l}7(2- \\
14.5)\end{array}$ & $\begin{array}{l}9(3.5- \\
12.0)\end{array}$ & 0.116 & $\begin{array}{l}6.5(2- \\
14.5)\end{array}$ & $\begin{array}{l}8.5 \\
(3.75- \\
16.5)\end{array}$ & 0.008 & $1(0-2)$ & $\begin{array}{l}1(0- \\
2)\end{array}$ & 0.806 \\
\hline $\begin{array}{l}\text { Joint } \\
\text { space } \\
\text { narrowing } \\
(0-8)\end{array}$ & $3(3-4)$ & $\begin{array}{l}4(3- \\
4)\end{array}$ & 0.034 & $\begin{array}{l}3(0.75- \\
4)\end{array}$ & $\begin{array}{l}3.5(1- \\
4)\end{array}$ & 0.059 & $0(0-0)$ & $\begin{array}{l}0(0- \\
0)\end{array}$ & 0.215 \\
\hline $\begin{array}{l}\text { Sclerosis } \\
(0-8)\end{array}$ & $2(1-3)$ & $\begin{array}{l}2(1- \\
3)\end{array}$ & 0.273 & $\begin{array}{l}2(0.75- \\
3)\end{array}$ & $2(0-4)$ & 0.018 & $0(0-1)$ & $\begin{array}{l}0(0- \\
0.25)\end{array}$ & 1.000 \\
\hline \multicolumn{10}{|c|}{ Results are presented in median (Q1-Q3). } \\
\hline
\end{tabular}

\section{Changes in CT scores of the SIJs over time}

The median (Q1-Q3) SIJ score at baseline in the delivery group and controls was 13 (8-22) and 11 (6-22), and the median progression was $1.5(0-3)$ and $1(0-2)$, respectively (Table 2$)$. The total SIJ score significantly increased during the median 2.9 years of follow-up in both groups $(p<0.05)$ (Fig. 3). However, no 
differences in the absolute changes in the total, erosion, JSN, and sclerosis scores of the SIJs per time point were observed between the delivery group and controls $(p=0.471)$ (Fig. $2 \mathrm{C}, \mathrm{D})$. We analyzed the interval changes of SIJs according to the delivery method (CS $[n=9]$ vs. VD $[n=3]$ ) in the delivery group (data on the delivery method were missing for nine patients). The changes in the total SIJ score, TES, and JSN and sclerosis scores were comparable between the CS and VD groups (data not shown).

\section{Discussion}

The present study assessed, using CT, the radiographic progression of the spine and SIJs in women with AS with and without delivery. We found that the interval changes in the CT scores of the spine and SIJs were not significantly different between AS patients with and without delivery. The interaction between biomechanical stress and the innate immune response has been proposed as a cause of AS. According to animal models, mechanical strain can contribute to entheseal inflammation and new bone formation [3]. During pregnancy, the combination of mechanical and hormonal changes causes excessive load on the spine and pelvis and alterations of the pelvic ligaments, leading to pelvic and low back pain [16]. Ursin et al. reported that $70 \%$ of pregnant women with axial spondyloarthritis in the third trimester did not take any medication.

Discontinuation of TNFIs has been reported to be associated with disease flares in parous women with AS [8]. Therefore, we hypothesized that biomechanical stress and discontinuation of treatment could affect the radiographic progression of the SIJs and spine in patients with AS during pregnancy. However, our study results showed no association between childbirth and structural damage in women with AS.

A major advantage of using CT for the assessment of syndesmophytes is that CT visualizes the whole spine in the sagittal and coronal axes with many slices. CT imaging studies have shown that more extensive syndesmophytes and more progression occur in the thoracic spine than in the cervical or lumbar spine [17]. Indeed, the CTSS is a more detailed score for syndesmophyte growth, indicating a height reaching $>50 \%$ or $<$ $50 \%$ of the IDS, than the mSASSS, which indicates only the presence or absence of syndesmophytes [9]. Radiographic assessment of spinal progression in AS has been reported to have limited reliability [11]. However, we found that the CT scores had excellent interobserver reliability, consistent with a previous CTSS study [9]. With respect to SIJs, conventional radiography underestimated sacroiliitis compared with CT in the SIMACT (Sacrolliac Magnetic resonance CT) study [13]. Although CT provides complete visualization of structural damage, concerns about radiation exposure have traditionally limited its use in AS patients. However, the development of low-dose CT has led to a reduction in radiation dose and noise. The effective dose in low-dose CT of the whole spine was estimated to be approximately $4 \mathrm{mSv}$, which is still higher than that of radiography (4 mSv: total dose from cervical, lumbar, and pelvic radiography) [9]. Diekhoff et al. showed that the mean radiation exposure with low-dose CT of the SIJs was similar to that with conventional radiography ( 0.51 vs. $0.52 \mathrm{mSv}$ ), with a higher detection rate for sacroiliitis [13]. Indeed, an oblique scanning method for the SIJs could avoid radiation exposure to the ovaries and require fewer slices to cover the whole SIJs compared with axial scanning [18]. Improvement in software together with the ability to reduce the radiation dose could make $\mathrm{CT}$ a feasible method for the evaluation of structural damage in the spine and SIJs in the near future.

Spinal progression was found to be associated with the presence of baseline syndesmophytes, male sex, old age, smoking, high disease activity at baseline, and time-averaged CRP levels [19, 20]. An observational 2-year 
follow-up study on patients with AS using data from the SIAS (Sensitive Imaging in Ankylosing Spondylitis) study showed a mean (standard deviation [SD]) CTSS change score of 16 (21). In our study, the median (Q1Q3) CTSS change in the delivery group and controls was $1(0-3)$ and $0(0-1)$, respectively, during a similar interval. In the SIAS study, 84\% of the enrolled patients were men with a mean (SD) age of 50 (9.8) years, and $37 \%$ of the patients had elevated CRP levels at baseline and higher CTSS (whole spine mean [SD] score: 163 [126]). However, in our study, all patients with AS were women of a young age with a much lower CTSS at baseline (median [Q1-Q3] in the delivery group and controls: 19 [16-23] and 20 [13.25-27.75], respectively). Indeed, the median time-averaged CRP levels were within the normal range in both groups. The discrepancy in baseline characteristics could explain the different results of CTSS changes.

In a previous study, 60\% of women presenting with postpartum back pain without axial spondyloarthritis had positive magnetic resonance imaging (MRI) findings for sacroiliitis according to the Assessment of SpondyloArthritis International Society definition [21]. Eshed et al. also found that bone marrow edema (46\%) and subchondral sclerosis (26\%) were prevalent peripartum MRI findings [22]. However, we could not find a link between these inflammatory changes in the peripartum period and the structural progression of SIJs. Although conventional radiography has limitations in evaluating the SIJs owing to their irregular outline and obliquity, CT is a sensitive method for detecting erosions, bone sclerosis, and ankylosis, which also represent the reference standards for the detection of bony alterations in AS [23]. Although radiographic progression of the SIJs was detected by CT in both AS patients with and without delivery, no significant differences in the interval changes of total, erosion, sclerosis, and JSN scores of the SIJs were found in our study. We expected that women with AS would have increased sclerosis in the SIJs after delivery, such as osteitis condensans ilii [24]. However, the SIJ scores for sclerosis in the delivery group did not significantly change. Although the score changes were small, the changes in the JSN scores in the delivery group and in the erosion and sclerosis scores in the control group were significant. Semiquantitative scores were used to evaluate the structural damage of the SIJs. Further studies with detailed quantitative measurements, such as the number and size of erosions or the exact thickness of sclerosis, are needed to confirm our study results.

Our study suggested that the delivery method (CS or VD) does not affect the radiographic progression of SIJs in patients with AS. A recent study using a medical claims database also showed that changes in prescription did not significantly differ between CS and VD [25]. The SIJs are not a part of the pelvic inlet and cannot be mechanically affected during delivery. In the present study, the rate of CS ( $n=9,75 \%)$ was much higher than that of VD $(n=3,25 \%)$ in women with AS. However, the small sample size, especially in the VD group, limited the assessment of structural changes of the SIJs according to the delivery method.

The effect of nonsteroidal anti-inflammatory drugs (NSAIDs) on the inhibition of radiographic progression in AS is controversial. A randomized controlled trial of diclofenac failed to show that this NSAID can prevent structural progression in AS [26]. A post hoc analysis of the celecoxib trial identified that AS patients with elevated acute-phase reactants benefited from treatment with celecoxib with respect to radiographic progression [27]. In our study, most AS patients in the delivery group stopped their medications after the confirmation of pregnancy. NSAIDs were the most prescribed medications, and the proportion of patients taking TNFIs was small in both groups. Indeed, the median time-averaged CRP levels were within the normal range in both groups. Owing to the low disease activity and low use of TNFIs in our study population, 
treatment discontinuation in pregnancy could not make a significant difference in structural progression between the two groups.

Although it provided insights into the association of pregnancy and delivery with radiographic progression in AS, our study had several limitations. First, the statistical power was limited by the small sample size. The small number of patients with at least two CT evaluations in 2-4-year intervals, the relatively low prevalence of AS in female patients, and the low birth rate in Korea made it difficult to enroll participants in our study [28]. Second, the retrospective design of this study is a shortcoming. Certain clinical parameters, such as the Bath Ankylosing Spondylitis Disease Activity Index and the Ankylosing Spondylitis Disease Activity Score, could not be evaluated through retrospective chart reviews. Information on the delivery method was missing for nine patients. Third, the present study utilized preexisting scans, and the radiation dose of CT was not uniform between the two centers. Images were not reformatted into an oblique coronal view oriented parallel and perpendicular to the long axis of the sacrum. A total of 24 regions of the SIJs were scored in the SIMACT study [13]. However, only four segments with coronal and sagittal views were analyzed in our study, which could have led to a low detection of radiographic progression in the SIJs.

\section{Conclusion}

The present study found that pregnancy and delivery have no effects on the radiographic progression of the spine and SIJs in female patients with AS based on CT scoring methods. Our study results can be provided to women with AS who are planning to conceive, for informative and educational purposes.

\section{Abbreviations}

AS: Ankylosing spondylitis; SIJ: sacroiliac joints; TNFi: tumor necrosis factor inhibitor; CS: Cesarean section; CTSS: computed tomography syndesmophyte score; mSASSS: modified Stoke Ankylosing Spondylitis Spine Score; VD: vaginal delivery; HLA-B27: human leucocyte antigen-B27; CRP: C-reactive protein; IRB: institutional Review board; VUs: vertebral units; IDS: intervertebral disc space; ICC: intraclass correlation coefficient; IDS: intervertebral disc space; TES: total erosion score; SIMACT: Sacrolliac Magnetic resonance CT; SIAS: sensitive imaging in ankylosing spondylitis; SD: standard deviation; MRI: magnetic resonance imaging; NSAIDs: Nonsteroidal anti-inflammatory drugs

\section{Declarations}

\section{Ethics approval and consent to participate}

This study was conducted in accordance with the Declaration of Helsinki and approved by the institutional Review board (IRB) of the Gangdong Kyung Hee University Hospital (2019-08-012) and Konkuk University Medical Center with a waiver of informed consent (KUH1011006).

\section{Consent for publication}

The informed consent was waived under the IRB authority due to retrospective nature of the study and analysis used anonymous clinical data 
The datasets generated and/or analyzed in this study are available from the corresponding author upon reasonable request.

\section{Competing interests}

The authors declare that they have no competing interests.

\section{Funding}

This research was supported by a grant of the Basic Science Research Program through the National Research Foundation of Korea funded by the Ministry of Education, Science and Technology, Republic of Korea (NRF-2021R1A2C1010075).

\section{Authors' contributions}

KAL, HRK, and SHL were involved in study conception and design. KAL, SYL, SHK, abd HSK were involved in data acquisition. KAL and SHL performed data analysis and interpretation. All authors were involved in the drafting or critical revision of the article, and all authors approved the final version for publication. HRK and SHL had full access to all of the data in the study and takes

\section{Acknowledgments}

None

\section{References}

1. Taurog JD, Chhabra A, Colbert RA. Ankylosing Spondylitis and Axial Spondyloarthritis. N Engl J Med 2016;374(26):2563-74.

2. Rusman T, van Bentum RE, van der Horst-Bruinsma IE. Sex and gender differences in axial spondyloarthritis: myths and truths. Rheumatology (Oxford). 2020;59(suppl4):iv38-iv46.

3. Jacques $P, M c G o n a g l e ~ D$. The role of mechanical stress in the pathogenesis of spondyloarthritis and how to combat it. Best Pract Res Clin Rheumatol 2014;28(5):703-10.

4. Bergström C, Persson M, Mogren I. Pregnancy-related low back pain and pelvic girdle pain approximately 14 months after pregnancy - pain status, self-rated health and family situation. BMC Pregnancy Childbirth. 2014;14:48.

5. Desai RJ, Huybrechts KF, Bateman BT, Hernandez-Diaz S, Mogun H, Gopalakrishnan C, et al. Brief Report: Patterns and Secular Trends in Use of Immunomodulatory Agents During Pregnancy in Women With Rheumatic Conditions. Arthritis Rheumatol 2016;68(5):1183-9.

6. van den Brandt S, Zbinden A, Baeten D, Villiger PM, Østensen M, Förger F. Risk factors for flare and treatment of disease flares during pregnancy in rheumatoid arthritis and axial spondyloarthritis patients. Arthritis Res Ther 2017;19(1):64. 
7. Pons M, Dougados M, Costedoat-Chalumeau N, Briot K, Goupille P, Roux C, et al. Pregnancy rates and outcomes in early axial spondyloarthritis: An analysis of the DESIR cohort. Joint Bone Spine 2021:88(2):105075.

8. Ursin K, Lydersen S, Skomsvoll JF, Wallenius M. Disease activity during and after pregnancy in women with axial spondyloarthritis: a prospective multicentre study. Rheumatology (Oxford) 2018;57(6):1064-71.

9. de Bruin F, de Koning A, van den Berg R, Baraliakos X, Braun J, Ramiro S. Development of the CT Syndesmophyte Score (CTSS) in patients with ankylosing spondylitis: data from the SIAS cohort. Ann Rheum Dis 2018;77(3):371-7.

10. van der Heijde D, Braun J, Deodhar A, Baraliakos X, Landewé R, Richards HB, et al. Modified stoke ankylosing spondylitis spinal score as an outcome measure to assess the impact of treatment on structural progression in ankylosing spondylitis. Rheumatology (Oxford) 2019;58(3):388-400.

11. Aydin SZ, Kasapoglu Gunal E, Kurum E, Akar S, Mungan HE, Alibaz-Oner F, et al. Limited reliability of radiographic assessment of spinal progression in ankylosing spondylitis. Rheumatology (Oxford) 2017;56(12):2162-9.

12. Tan S, Ward MM. Computed tomography in axial spondyloarthritis. Curr Opin Rheumatol 2018;30(4):3349.

13. Diekhoff T, Hermann KG, Greese J, Schwenke C, Poddubnyy D, Hamm B, et al. Comparison of MRI with radiography for detecting structural lesions of the sacroiliac joint using CT as standard of reference: results from the SIMACT study. Ann Rheum Dis 2017;76(9):1502-8.

14. van der Linden S, Valkenburg HA, Cats A. Evaluation of diagnostic criteria for ankylosing spondylitis. A proposal for modification of the New York criteria. Arthritis Rheum 1984;27(4):361-8.

15. Park JW, Kim MJ, Lee JS. Impact of Tumor Necrosis Factor Inhibitor Versus Nonsteroidal Antiinflammatory Drug Treatment on Radiographic Progression in Early Ankylosing Spondylitis: Its Relationship to Inflammation Control During Treatment. Arthritis Rheumatol 2019;71(1):82-90.

16. Aldabe D, Milosavljevic S, Bussey MD. Is pregnancy related pelvic girdle pain associated with altered kinematic, kinetic and motor control of the pelvis? A systematic review. European spine journal : official publication of the European Spine Society, the European Spinal Deformity Society, and the European Section of the Cervical Spine Research Society. Eur Spine J 2012;21(9):1777-87.

17. de Koning A, de Bruin F, van den Berg R, Ramiro S. Low-dose CT detects more progression of bone formation in comparison to conventional radiography in patients with ankylosing spondylitis: results from the SIAS cohort. Ann Rheum Dis 2018;77(2):293-9.

18. Li SG, Liu X, Zhou H, Zhang Q. Interrater reliability and radiation dosage of oblique coronal computed tomography for sacroiliitis in comparison with axial computed tomography. Br J Radiol 2018;91(1081):20150700.

19. Konsta M, Sakellariou GT, Rusman T, Sfikakis PP, Iliopoulos A, van der Horst-Bruinsma IE. Long-term effect of TNF inhibitors on radiographic progression in ankylosing spondylitis is associated with timeaveraged CRP levels. Joint Bone Spine 2020;88(3):105111.

20. Aouad K, Ziade N, Baraliakos X. Structural progression in axial spondyloarthritis. Joint Bone Spine 2020;87(2):131-6. 
21. de Winter J, de Hooge M, van de Sande M, de Jong H, van Hoeven L, de Koning A, et al. Magnetic Resonance Imaging of the Sacroiliac Joints Indicating Sacroiliitis According to the Assessment of SpondyloArthritis international Society Definition in Healthy Individuals, Runners, and Women With Postpartum Back Pain. Arthritis Rheumatol 2018;70(7):1042-8.

22. Eshed I, Miloh-Raz H, Dulitzki M, Lidar Z, Aharoni D, Liberman B, et al. Peripartum changes of the sacroiliac joints on MRI: increasing mechanical load correlating with signs of edema and inflammation kindling spondyloarthropathy in the genetically prone. Clin Rheumatol 2015;34(8):1419-26.

23. Leone A, Cassar-Pullicino VN, D'Aprile P, Nasuto M, Guglielmi G. Computed Tomography and MR Imaging in Spondyloarthritis. Radiol Clin North Am 2017;55(5):1009-21.

24. Parperis K, Psarelis S. Osteitis condensans ilii: current knowledge and diagnostic approach. Rheumatol Int 2020;40(7):1013-9.

25. Lee JS, Oh JS. Effects of Pregnancy and Delivery Methods on Change in Ankylosing Spondylitis Treatment Using the Korean Health Insurance Review and Assessment Service Claims Database. J Korean Med Sci 2019;34(37):e238.

26. Sieper J, Listing J, Poddubnyy D, Song IH, Hermann KG, Callhoff J, et al. Effect of continuous versus ondemand treatment of ankylosing spondylitis with diclofenac over 2 years on radiographic progression of the spine: results from a randomised multicentre trial (ENRADAS). Ann Rheum Dis 2016;75(8):1438-43.

27. Kroon F, Landewé R, Dougados M, van der Heijde D. Continuous NSAID use reverts the effects of inflammation on radiographic progression in patients with ankylosing spondylitis. Ann Rheum Dis 2012;71(10):1623-9.

28. Song JE, Ahn JA. Factors related to low birth rate among married women in Korea. PloS One 2018;13(3):e0194597.

\section{Figures}


a

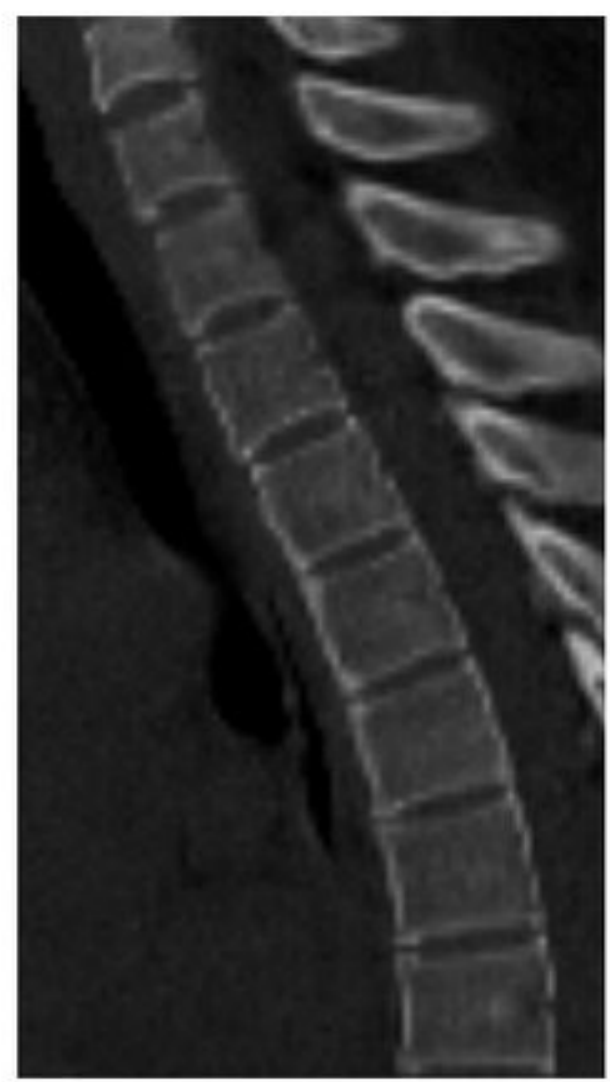

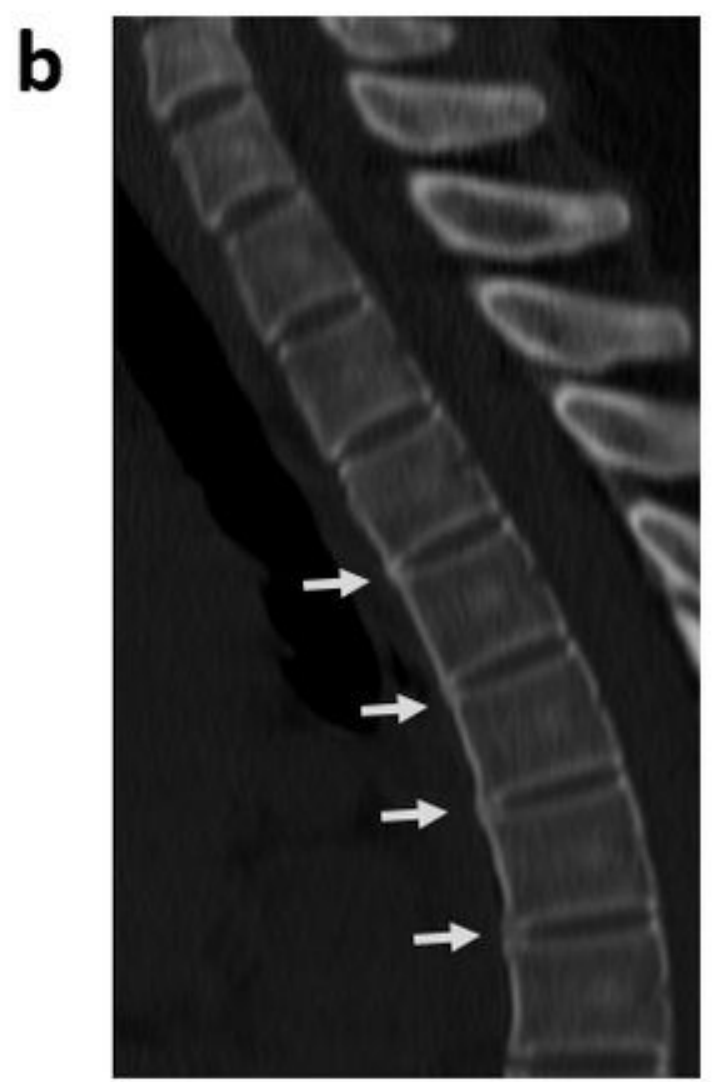

\section{Figure 1}

Sagittal-view CT image of T-spine at baseline (a) and follow-up (b) in women with AS. At the anterior side of vertebral units (VUs) T3-T4 down to T6-T7 (white arrows), newly developed syndesmophytes are seen. CT: computed tomography, T-spine: thoracic spine; AS: ankylosing spondylitis 


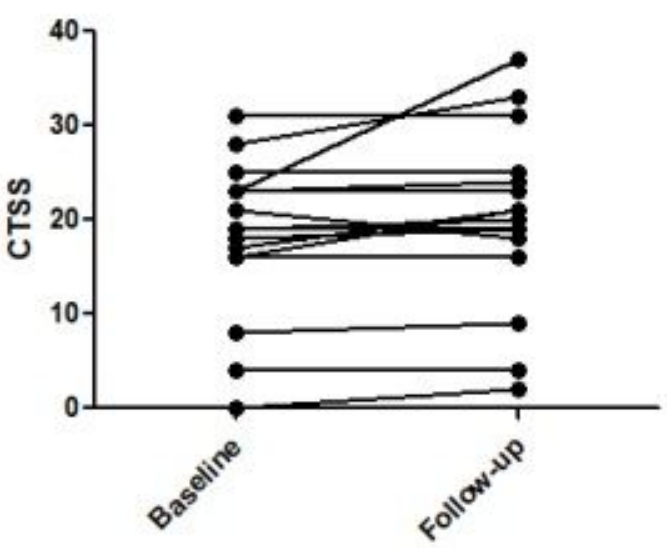

C

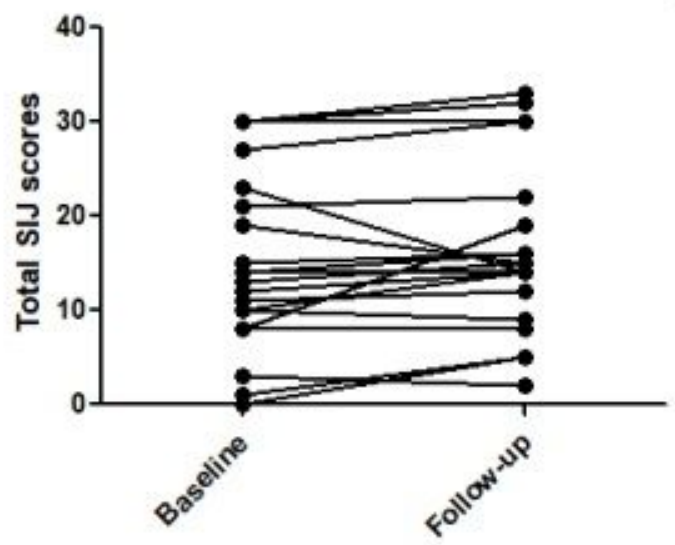

b

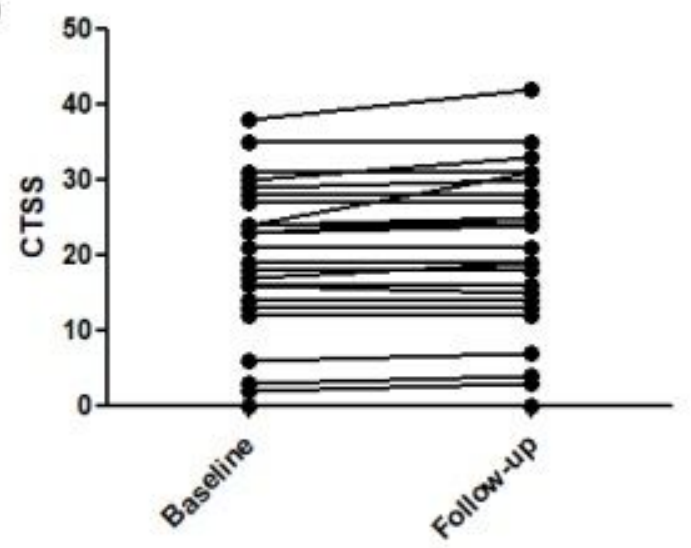

d

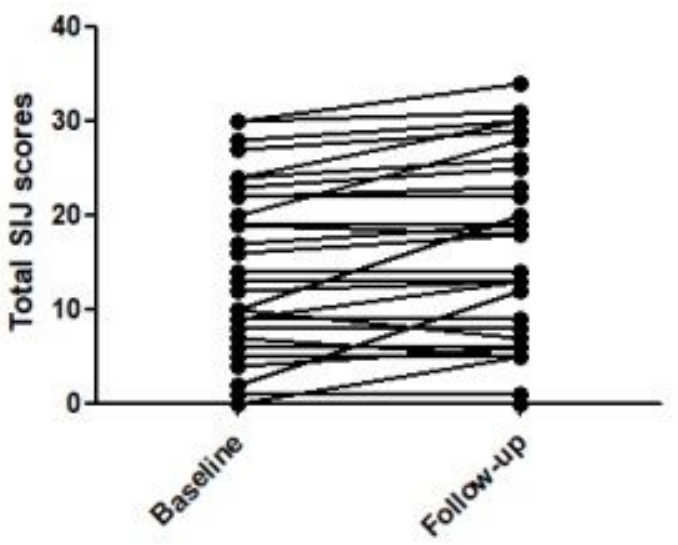

Figure 2

Changes in the CTSS and total SIJ scores during follow-up. Women with ankylosing spondylitis (AS) in the delivery group $(a, c)$. Women with AS in the control group $(b, d)$. Connected dots indicate the CT scores at different time points in the same patient. CTSS: computed tomography syndesmophyte score, SIJ: sacroiliac joint

a

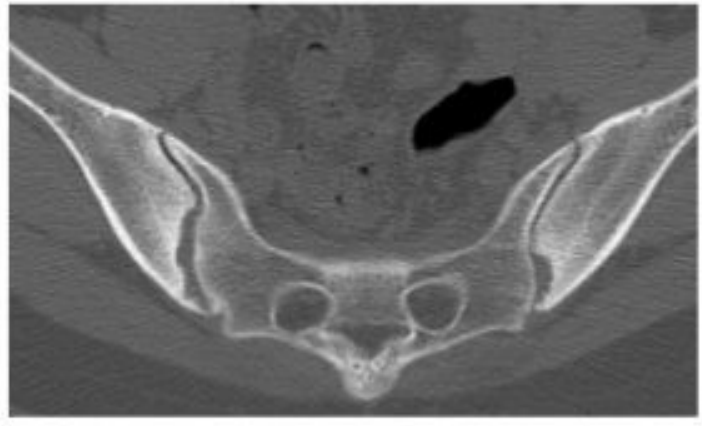

b

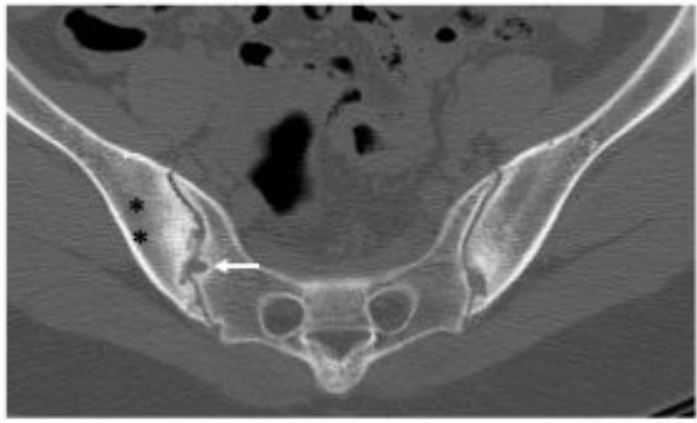

Figure 3

Coronal-view CT scans of SIJ at baseline (a) and follow-up (b) in women with AS. New bone erosion in the right sacral side (white arrow) and sclerosis (asterisk) in the right iliac side are noted in follow-up CT. CT: computed tomography, SIJ: SIJ: sacroiliac joint, AS: ankylosing spondylitis 
This is a list of supplementary files associated with this preprint. Click to download.

- SupplementaryFilel.docx 